\title{
3 Research Suare

\section{Anatomical Dissection as a Source of Clinically Relevant Findings with Potential Medico-Legal Implications}

\section{Veronika Dzetkuličová}

Masaryk University

\section{Petr Handlos}

University Hospital Ostrava

\section{Tomáš Vojtíšek}

St. Anne University Hospital in Brno, Masaryk University

Marek Joukal ( $\nabla$ mjoukal@med.muni.cz)

Masaryk University

\section{Research Article}

Keywords: anatomical dissection, autopsy, extrapericardial diaphragmatic hernia, iatrogenic hernia

Posted Date: February 25th, 2022

DOI: https://doi.org/10.21203/rs.3.rs-1385682/v1

License: (c) (i) This work is licensed under a Creative Commons Attribution 4.0 International License. Read Full License 


\section{Abstract}

\section{Purpose}

Bodies bequeathed to anatomical departments of medical schools in the Czech Republic for anatomical teaching and research belong to donors whose manner of death is deemed natural and does not require further investigation with medico-legal autopsies. However, there are rare cases when critical medico-legal findings related to the cause/manner of death or clinically relevant past surgical procedures can be found during anatomical dissection. This article also adds to the wealth of literature supporting the argument that pathologies and clinically relevant findings encountered by medical students during anatomical dissection are an opportunity for problem-based learning and integration of clinically oriented modules into early undergraduate phases of medical degree curricula.

\section{Methods}

This article gives an example of an extrapericardial iatrogenic diaphragmatic hernia which was most likely caused by instrument manipulation during a thoracic surgical procedure and went unobserved for three years until the body was subject to anatomical dissection.

\section{Results}

Although this clinical finding was most likely unconnected to the cause of death of the donor, the case is a cautionary example that bodies undergoing anatomical dissection could contain evidence of previous surgical incaution during invasive procedures.

\section{Conclusions}

For the benefit of anatomical technicians and educators, this article also points out some examples when signs of suspicious death could be overlooked by medical professionals who establish a cause of death in bodies which could be a subject to body fixation and subsequent anatomical dissection.

\section{Introduction}

Anatomical dissection is a dissection performed systematically to study the gross anatomy of the full human body hands-on while appreciating and recording normal and pathological arrangements and relationships of the body's relevant structures [1-3]. Multiple studies show students benefitting from an in-depth discussion of various pathological findings with a clinician during anatomical dissection [4-10]. Such opportunities help the students link anatomical structures with clinical implications enhancing their pre-clinical curriculum.

Based on the legally binding requirements in the Czech Republic, it is assumed that bodies donated for anatomical dissection will have the cause of death established as unsuspicious and the manner of death will be natural. However, there is a potential for medical professionals certifying death to make a mistake 
and establish a wrong cause of death [11]. Not all misdiagnosed causes of death would have to be obvious for the medical doctor certifying the cause of death, nor would they automatically have to be causes for immediate concern. Plummer et al. (2018) report findings of additional pathologies which were uncovered during anatomical dissections in $66 \%$ of 84 cadavers included in their study [12]. The pathologies in those cases were unrelated to the cause of death stated in the accompanying death certificate. The paper does not mention if there were any of that $66 \%$ which could have potentially been cases with misdiagnosed causes of death, but the authors mention that there is a potential for extremely rare cases where coroner could miss some important findings related to the cause of death. The authors also note the importance of having institutional mechanisms in place that would allow for family notification in cases of significant pathological findings adding to the cause of death [12]. In the Czech Republic, there are no such mechanisms in place and the additional pathologies and/or clinically significant findings are not reported to the families of donors but the legal requirements to report any suspicious finding suggesting any unlawful involvement remain the same as in the case of other types of autopsies [13].

Since not all of the anatomy educators/technicians are also trained medical doctors, and those who are might not necessarily be trained forensic pathologists, there could be an increased potential to miss subtle medico-legal findings in bodies dedicated to anatomical dissection, especially when the bodies are accompanied by a death certificate confirming their natural cause of death. Furthermore, if the anatomical dissection is performed on embalmed bodies, the process of fixation may alter the diagnostic value of the tissues [14]. In such cases, should a clarification on the cause of death in a form of autopsy be needed, the embalming process could seriously hamper the examination.

The paper aims to raise awareness amongst anatomy educators, students of anatomy, and staff preparing the body for anatomical dissection about the potential to uncover critical findings related to the cause and manner of death and/or surgical complications during anatomical dissection. The authors use an example of extrapericardial iatrogenic diaphragmatic hernia detected in a body during anatomical dissection. To our knowledge, this case is the first one to be described in the literature and could serve as a cautionary notice to anatomy educators and present/future medical professionals raising awareness of potential complications occurring during routine thoracic surgical procedures as well as adding to the wealth of clinically relevant findings that bodies of donors offer during anatomical dissection.

\section{Case Example}

A 66 years-old female, who bequeathed her body to the Department of Anatomy at the Medical Faculty of Masaryk University in Brno (Czech Republic), died suddenly at home. The cause of death was reported as a cardiac arrest and her body was transported to the Department of Anatomy. According to available medical records, this patient suffered from three-vessel coronary disease and underwent a coronary artery bypass graft three years before the patient's death; the left internal thoracic artery was attached to the left anterior descending artery with a venous graft to the right coronary artery. The body had been embalmed and a standard anatomical dissection of the neck, thorax, and abdominal region was performed. When 
the abdominal cavity was opened, the greater omentum was found adhering to the diaphragm. A small defect in the muscular part of the diaphragm filled by the omentum was observed upon detailed examination. This circular defect (diameter of $13 \mathrm{~mm}$; Fig. 1A) was reinforced by fibrous tissue on its margin. Part of the greater omentum passing through the muscular defect contained blood vessels that were recognized as branches of the left gastroomental artery (Fig. 1B). An intrathoracic part (106 mm long) containing blood vessels was found in the left pleural cavity next to the costodiaphragmatic recess (Fig. 1C and D).

[insert Figure 1]

Extrapericardial iatrogenic diaphragmatic herniae are very uncommon complications reported mainly in patients undergoing esophageal or thoracic surgery $[15,16]$. Most cases of extrapericardial herniae are congenital developmental disorders presented in neonates as respiratory distress, but many of them could remain undiagnosed and manifest later in life [17]. However, in our case, the margins and regular shape of the defect and by-pass surgery suggested iatrogenic origin. The diaphragmatic defect was most likely caused by a surgical sucker or chest tube insertion and as such is an unexpected complication in thoracic surgery. latrogenic extrapericardial diaphragmatic herniae were reported as rare complications of Nissen fundoplication and esophagectomy $[16,18]$. This case is unique in two aspects. Firstly, the localization of the defect in the left costodiaphragmatic angle is unusual in patients after heart surgery and secondly, the hernia was revealed three years after surgery during a standard anatomical dissection. The finding was deemed unconnected to the cause of death of the patient and the manner of death remained classified as natural (cardiac arrest).

\section{Discussion}

From the perspective of students, it was a unique learning opportunity, as besides studying normal anatomy and morphology of the human body, they encountered and discussed clinical findings which, under different circumstances, could have developed into a serious complication. This case was a good example of shifting the classic focus of anatomical dissection from the teaching of human anatomy to clinically important findings that were revealed during anatomical dissection $[4,6-10]$. Furthermore, similar critical clinical findings and rare findings with potential medico-legal implications revealed during anatomical dissection could be a cautionary note for future medical professionals to be mindful of various possible complications which may occur during routine surgical procedures. Although this particular case was classified as death resulting from natural causes, it also inspired the authors to look into the literature about any potential medico-legal findings related to the cause and manner of death that could be uncovered during anatomical dissection.

According to the International Federation of Associations of Anatomists (IFAA), a willed body donation is recommended as the sole source of cadaveric material for anatomical dissection $[3,19,20]$. However, every country has its legal requirements for regulating the donation of a dead body for anatomical dissection $[3,21]$. The Czech Republic is amongst the countries which are using bodies of donors who, 
during their life, agreed to bequeath their bodies after death to the anatomical departments of universities for anatomical teaching, and for scientific and research purposes $[3,13]$. Occasionally, the consent can be given by the relatives of the donor, however, this scenario occurs rarely and only in a specific set of circumstances. Further conditions of acceptance of the bequeathed body to anatomical departments in the Czech Republic is that their body is not to be an object of any type of autopsy, for example, a medicolegal autopsy in a case of a criminal act, and that the cause of death of the donors must be clear and manner of death deemed as natural [13].

However, the assumption that everyone who decided to donate their body for anatomical education and research has died naturally could be incorrect. Especially in the cases of elderly individuals, who are most abundant age category of body donors, signs of active violence caused by another person, medical malpractice, or suicide by poisoning could be overlooked by the medical practitioner who certifies the cause of death $[12,22]$. Moreover, in the cases when death occurs outside of hospitals, the determination of the cause of death is more likely to be less precise [23-25]. Due to the elderly nature of most body donors, they are usually suffering from a variety of conditions naturally connected to their age, they occasionally live alone which could complicate gaining precise information about their health status before death. It is a combination of these factors which can lead to underestimation of discrete trauma changes by the medical doctor who is attending and examining the deceased. For example, some of the authors of this text have repeatedly met with overlooked signs of smothering, during their time practicing forensic pathology. Similarly, in cases of deceased who suffered from micronodular liver cirrhosis or blood coagulation disorders, the findings of bleeding under the soft brain meninges as a result of head blunt force trauma were minimal and could be overlooked [26]. The authors have also encountered minimal findings of such bleeding as a result of blunt force trauma to the head even in cases where anamnesis of micronodular liver cirrhosis was not present. Another injury that could be inapparent could be an injury to parenchymal organs caused by blunt surface force applied against the thorax or abdomen resulting in fatal bleeding into thoracic/abdominal cavities [27].

Every country's criminal justice system contains some form of requirements for mandatory reporting of findings that could have led to the death of an individual. In the Czech Republic, the person performing an autopsy, or any dissection of the deceased must notify the police if they encounter any suspicious finding suggesting any unlawful involvement [13]. Naturally, this scenario is more frequent during standard autopsies performed due to unknown causes of death of an individual rather than during anatomical dissection. Based on data from Nielsen et al. (1991), there is a possibility that even during an anatomical dissection, a case of suspicious death may be detected despite the lack of literature reporting such cases [11]. Subsequent notification and involvement of police and forensic experts must be ensured despite the effect a post-mortem body fixation may have on the results of forensic and police investigations in these potentially rare cases.

In the Czech Republic, anatomical dissections are performed on embalmed bodies. Bodies of donors are perfused with a fixative solution and subsequently immersed in this solution for weeks or months, depending on the type of the solution. The result is a body that is free from most potentially dangerous 
pathogens and in which the autolytic processes of decomposition are stopped. The fixatives cause protein coagulation as well as fixation of nervous tissues of the brain which contain lipids. However, should a need for an autopsy arise in a body which is already embalmed, such fixation processes could seriously hamper the examination. Determination of causes of death according to the rules of a standard autopsy is extremely difficult in cases of embalmed bodies [14]. Macroscopic evaluation of any relevant changes to soft tissues is especially difficult in bodies that underwent chemical fixation. In cases where an autopsy reveals criminal involvement, body embalming can complicate any investigation performed by law enforcement institutions, especially in cases of delayed examination of a potential crime scene. Another problematic group of bodies where embalming can prohibit successful and/or precise determination of death cause are intoxicated individuals $[14,28]$. Due to the fixation of bodies with a solution including ethanol, it is not possible to perform a reliable toxicologic examination to ascertain the presence of ethanol in the body at the time of death. In contrast, hidden traumatic damage of bones can be examined even in embalmed individuals where the embalming preserves the tissues for a long time after death than in non-embalmed bodies [28]. Formaldehyde fixation specifically does not affect the macroscopic forensic examination of fractured bones especially when imaging techniques of postmortem radiology, such as post-mortem X-ray, post-mortem $C T$, are employed $[29,30]$. A further factor that could obscure details suggesting an unnatural cause of death is the manner of body fixation, especially in the case of initial vascular perfusion. Depending on the site of the perfusion, the soft tissue around the region will be disturbed due to the insertion of the cannula. For the cases where embalming fluid is introduced into the body via the common carotid artery and/or internal jugular vein, the signs of soft tissue damage in the neck area may be obscured by this procedure [31]. It is therefore important to pay attention and perform a detailed surface examination of the body especially in the areas of and before initial vascular perfusion. Figures 2 and 3 contain a summary of various cases when bodies may exhibit often overlooked signs which could indicate an unnatural cause of death. Moreover, the authors recommend that anatomy educators and technicians without formal medical education consult their appropriate colleagues (anatomists with medical degrees, forensic pathologists) if there is any suspicion of critical medico-legal findings related to the cause/manner of death or relevant past surgical procedures. It is also recommended to photograph/document the suspicious area and consult a forensic pathologist before any invasive procedure takes place.

[insert Figure 2 and 3]

\section{Conclusionsconclusions And Recommendations}

In conclusion, encountering iatrogenic clinical findings during anatomical dissection is a beneficial learning experience which students of medicine may acquire during the pre-clinical phase of their studies. Anatomy educators and technicians should proceed with caution and if any suspicions about the body's cause of death are raised, secure photographic documentation of the body and consult with medical professionals who declared the death of the donor and/or forensic pathologists. Since the fixation of the body may destroy/obscure evidence of suspicious causes of death in donors, bodies should undergo detailed surface examination before any invasive procedures connected to embalming are performed. 
Forensic pathologists should be also consulted in suspicious cases of pathological findings during anatomical dissection for the benefit of donors and their families.

\section{Declarations}

\section{Author Contribution}

V Dzetkulicova: manuscript writing/editing

P Handlos: data analysis, manuscript writing/editing

T Vojtíšek: data analysis, manuscript writing/editing

M Joukal: project development, data collection, manuscript writing/editing

Funding

No funding was received to assits with the preparation of this manuscript.

\section{Competing interests}

The authors have no relevant financial or non-financial interests to disclose.

\section{Compliance with Ethical Standards}

This study was performed in line with the principles of the Declaration of Helsinki. Informed consent was obtained from body donor upon their signing the body donation agreement.

\section{References}

1. Rizzolo LJ, Stewart WB (2006) Should we continue teaching anatomy by dissection when ... Anat Rec B New Anat 289:215-218. https://doi.org/10.1002/AR.B.20117

2. Wilson $\mathrm{AB}$, Miller $\mathrm{CH}$, Klein $\mathrm{BA}$, et al (2018) A meta-analysis of anatomy laboratory pedagogies. Clin Anat 31:122-133. https://doi.org/10.1002/CA.22934

3. Habicht JL, Kiessling C, Winkelmann A (2018) Bodies for Anatomy Education in Medical Schools: An Overview of the Sources of Cadavers Worldwide. Acad Med 93:1293-1300. https://doi.org/10.1097/ACM.0000000000002227

4. Wood A, Struthers K, Whiten S, et al (2010) Introducing gross pathology to undergraduate medical students in the dissecting room. Anat Sci Educ 3:97-100. https://doi.org/10.1002/ASE.136

5. Ellis $\mathrm{H}$ (2001) Teaching in the dissecting room. Clin Anat 14:149-151

6. Chun J, Theologou T, Ellis H (2007) Incidence of cardiovascular disease in the dissecting room: a valuable teaching asset. Clin Anat 20:89-92. https://doi.org/10.1002/CA.20340 
7. Magrill D (2008) Intra-abdominal pathology in the dissecting room: a study of incidence and its value in teaching. Anat (International J Exp Clin Anatomy) 2:22-29. https://doi.org/10.2399/ANA.08.022

8. Zhang G, Fenderson BA (2014) Pathology Encountered During Cadaver Dissection Provides an Opportunity for Integrated Learning and Critical Thinking. Austin J Anat 1:1027

9. Geldenhuys EM, Burger EH, van Helden PD, et al (2016) Optimizing the use of cadavers by integrating pathology during anatomy dissection. Anat Sci Educ 9:575-582. https://doi.org/10.1002/ASE.1617

10. Wood A, Whiten S, McVee J, et al (2015) Histopathology from the dissecting room: are cadavers a suitable source of educationally useful histopathology specimens? Anatomy 9:26-33. https://doi.org/10.2399/ANA.14.048

11. Nielsen GP, Björnsson J, Jonasson JG (1991) The accuracy of death certificates. Implications for health statistics. Virchows Arch A Pathol Anat Histopathol 419:143-146. https://doi.org/10.1007/BF01600228

12. Plummer M, Vasilyev A, Shaheen S, et al (2018) Pathology Findings in Medical School Anatomy Cadavers. MedEdPublish 7:. https://doi.org/10.15694/MEP.2018.000007.1

13. The Ministry of Heath Czech Republic (2011) The Act on Healthcare Services No.372/2011

14. Criss BE, Powers RH, Topmiller RG, Dean DE (2017) Detection of methanol in a subdural hematoma after embalming. Acad Forensic Pathol 7:S72-S146. https://doi.org/10.1177/192536211700701S02

15. Takanami I (2003) Hernia of the diaphragm with gastric ulcer and volvulus: an unusual complication after diaphragmatic resection by VATS. Interact Cardiovasc Thorac Surg 2:544-546. https://doi.org/10.1016/S1569-9293(03)00124-5

16. Hamaloglu E, Topaloglu S, Törer N (2002) Diaphragmatic herniation after transhiatal esophagectomy. Dis Esophagus Off J Int Soc Dis Esophagus 15:186-188. https://doi.org/10.1046/J.1442-2050.2002.00233.X

17. Robertson J, Avjioglu E (2007) Strangulated stomach within a paraoesophageal hernia: a rare complication of laparoscopic Nissen fundoplication. Australas Radiol 51 Suppl:B250-B252. https://doi.org/10.1111/J.1440-1673.2007.01829.X

18. Waller DA, Satur CM, Mitchell IM, Sivanathan UM (1992) latrogenic peritoneopericardial hernia following coronary artery bypass surgery. Eur J Cardio-thoracic Surg Off J Eur Assoc Cardio-thoracic Surg 6:156-157. https://doi.org/10.1016/1010-7940(92)90122-E

19. Ghosh SK (2020) The practice of ethics in the context of human dissection: Setting standards for future physicians. Ann Anat 232:151577. https://doi.org/10.1016/J.AANAT.2020.151577

20. International Federation of Associations of Anatomists (2012) Recommendations of good practice for the donation and study of human bodies and tissues for anatomical examination. Plexus 4-5

21. Riederer BM, Bueno-López J (2014) Anatomy, respect for the body and body donation - a guide for good practice. Eur J Anat 18:361-368 
22. Ohberg A, Lonnqvist J (1998) Suicides hidden among undetermined deaths. Acta Psychiatr Scand 98:214-218. https://doi.org/10.1111/J.1600-0447.1998.TB10069.X

23. Nashelsky MB, Lawrence CH (2003) Accuracy of Cause of Death Determination Without Forensic Autopsy Examination. Am J Forensic Med Pathol 24:313-319. https://doi.org/10.1097/01.PAF.0000097857.50734.C3

24. Vanatta PR, Petty CS (1987) Limitations of the forensic external examination in determining the cause and manner of death. Hum Pathol 18:170-174. https://doi.org/10.1016/S00468177(87)80335-0

25. Asnaes S, Paaske F (1980) Uncertainty of determining cause of death in a medicolegal material without autopsy. An autopsy study. Forensic Sci Int 15:103-114. https://doi.org/10.1016/03790738(80)90149-8

26. Leestma JE (2014) Forensic Neuropathology, 3rd ed. CRC Press, Boca Raton

27. Dokoupil M, Marecová K, Uvíra M, et al (2019) Fatal delayed hemopericardium and hemothorax following blunt chest trauma. Forensic Sci Med Pathol 15:272-275. https://doi.org/10.1007/S12024-018-0069-5

28. Nikolaou P, Papoutsis I, Dona A, et al (2013) Toxicological analysis of formalin-fixed or embalmed tissues: A review. Forensic Sci Int 233:312-319. https://doi.org/10.1016/J.FORSCIINT.2013.10.006

29. Öhman C, Dall'Ara E, Baleani M, et al (2008) The effects of embalming using a $4 \%$ formalin solution on the compressive mechanical properties of human cortical bone. Clin Biomech 23:1294-1298. https://doi.org/10.1016/J.CLINBIOMECH.2008.07.007

30. Chew FS, Relyea-Chew A, Ochoa ER (2006) Postmortem computed tomography of cadavers embalmed for use in teaching gross anatomy. J Comput Assist Tomogr 30:949-954. https://doi.org/10.1097/01.RCT.0000232473.30033.C8

31. Francis E (1915) Embalming: a satisfactory method of performing. Public Heal Reports 30:22232226

\section{Figures}



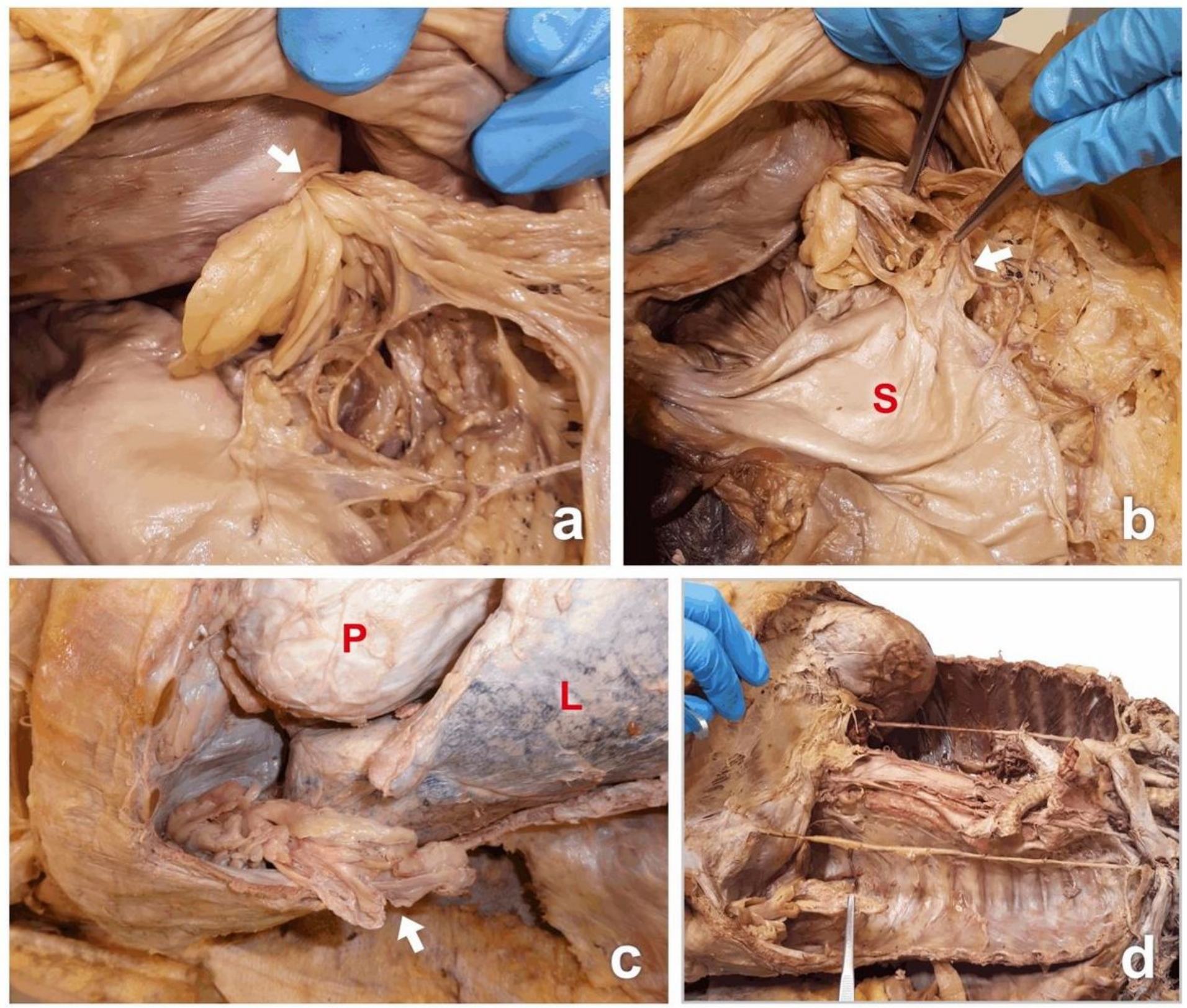

\section{Figure 1}

Diaphragmatic defect was surrounded by a fibrous ring (arrow; a); herniated omentum in the thoracic cavity was supplied by branches of the left gastroomental artery (arrow; b); atypical location of the diaphragmatic hernia in the left costal part of the diaphragm (arrow; $c)$; part of the greater omentum in the costodiaphragmatic recess of the left pleural cavity (in forceps; d); P - pericardium; L - lung; S stomach 

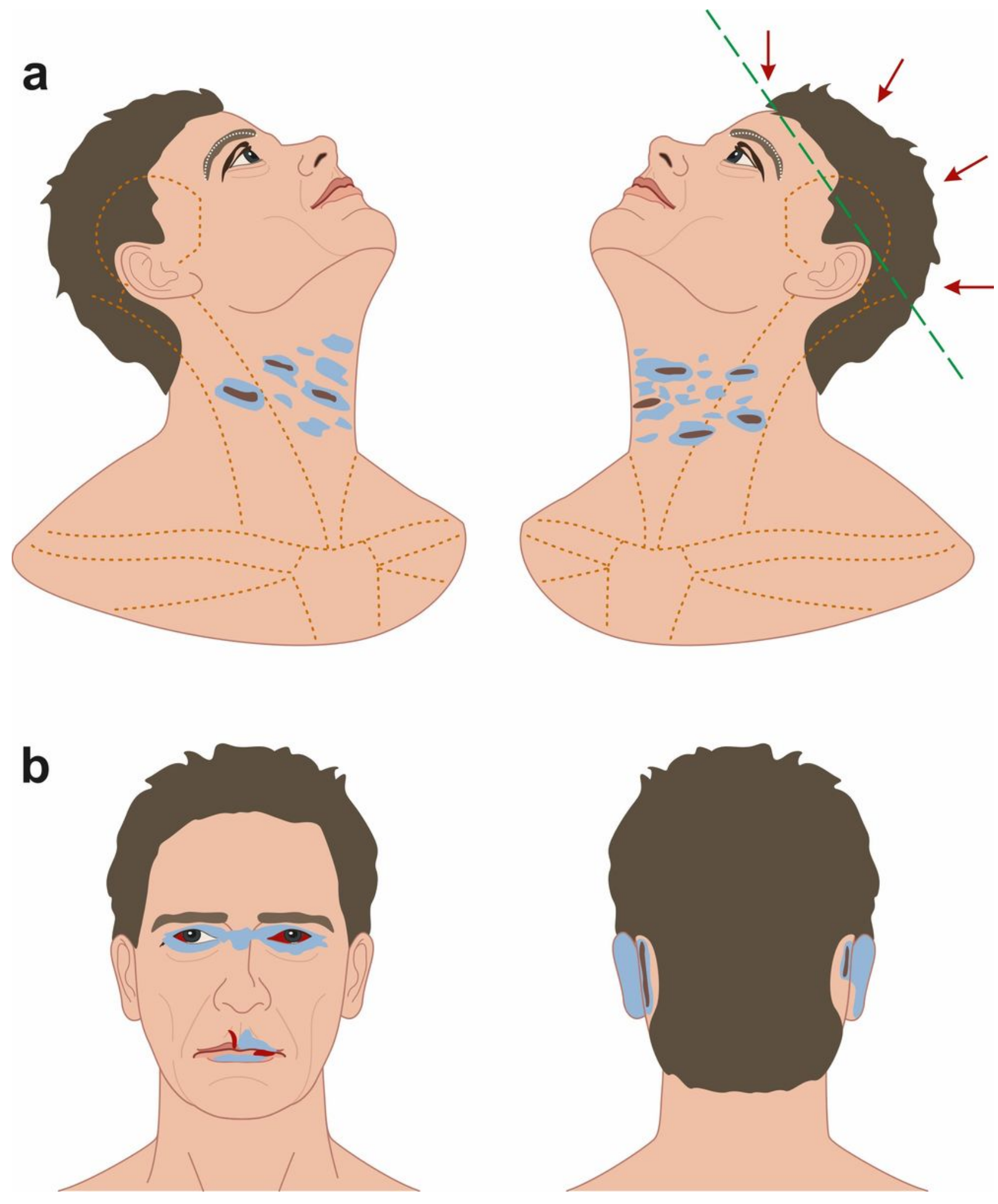

\section{Figure 2}

Injuries to the hairy part of the scalp (arrows above the dashed 'hat brim line'), anterior and lateral neck (a), together with the injuries to the central part of the face (orbit, root of the nose, lips) (b) are frequently encountered during forensic examinations as a result of active violence caused by another person/s 

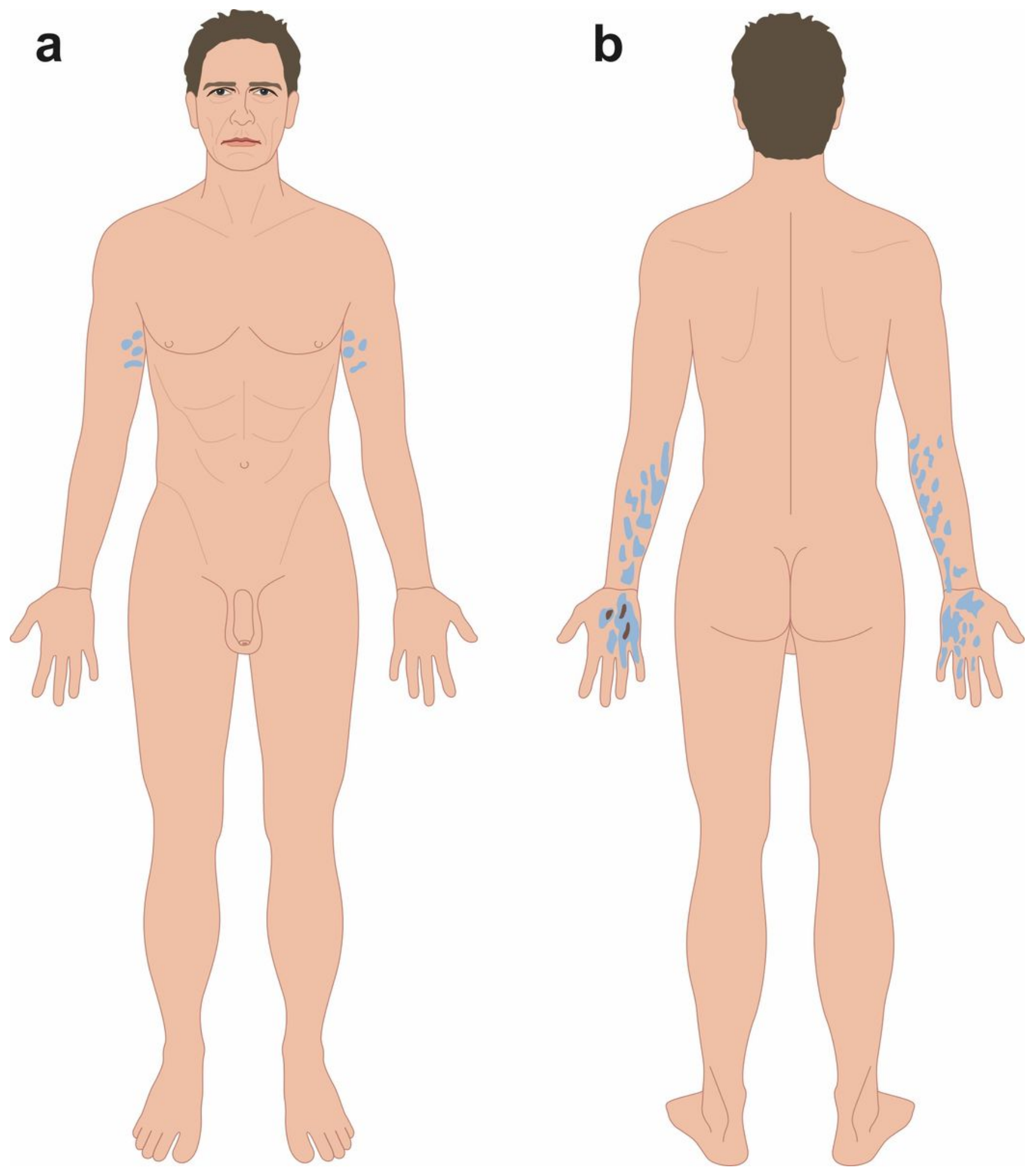

\section{Figure 3}

Oval bruises in the area of the medial arm (a) are often encountered during forensic body examinations in cases of manipulation with an incapacitated body; injuries localized on the dorsal surface of the forearms, hands, and/or digits (b) could suggest a form of self-defense 